\title{
The Prevalence of Metabolic Syndrome, Scoring and Comparison in People with and without COPD: Evidence From Shahrekord PERSIAN Cohort Study
}

\section{Fatemeh Zeynab Kiani}

Shahrekord University of Medical Science

Ali Ahmadi ( $\square$ aliahmadi2007@gmail.com )

Shahrekord University of Medical Science https://orcid.org/0000-0002-1588-2136

\section{Research}

Keywords: Metabolic syndrome, Pulmonary Disease, Chronic Obstructive, PERSIAN cohort, Iran

Posted Date: May 11th, 2021

DOl: https://doi.org/10.21203/rs.3.rs-502427/v1

License: (a) (i) This work is licensed under a Creative Commons Attribution 4.0 International License. Read Full License

Version of Record: A version of this preprint was published at Metabolic Syndrome and Related Disorders on February 18th, 2022. See the published version at https://doi.org/10.1089/met.2021.0060. 


\section{Abstract \\ Background}

Comorbidities are common in patients with Chronic obstructive pulmonary disease (COPD), including metabolic syndrome (MetS). This study aimed to determine the prevalence of MetS and its components in people with and without COPD.

\section{Methods}

This population-based study was performed on 6961 adult years in the Shahrekord Prospective epidemiological research studies in Iran. Data collection, spirometry indexes and COPD diagnosis were performed according to the cohort protocol from 2015 to 2019. The data were analyzed by two-independent sample t-tests, chi-square, and logistic regression models. P-value $<0.05$ was considered as statistically significant. All analyses were conducted using stata statistical software: release 16 (stata Corp, College Station, Texas 77845 USA).

\section{Result}

The prevalence of MetS in patients with and without COPD was $28.4 \%$ and $31 \%$, respectively. The most common component of MetS in people with COPD was low high-density lipoprotein cholesterol (HDL-C) (47.4\%), waist circumference (WC) (43.9\%), and High fasting blood sugar (FBS) (39.3\%). There was a statistically significant difference in the frequency of respiratory problems between people with and without MetS. The age above 60 years $(\mathrm{OR}=2.20,95 \% \mathrm{Cl}: 1.72-2.80)$, woman gender $(\mathrm{OR}=1.36,95 \% \mathrm{Cl}: 1.49-$ 1.97), obesity $(\mathrm{OR}=11.17,95 \% \mathrm{Cl}: 9.02-13.62)$, illiterate education $(\mathrm{OR}=1.80,95 \% \mathrm{Cl}: 1.49-2.17)$, and living in urban $(\mathrm{OR}=1.96,95 \% \mathrm{Cl}: 1.64-2.35)$ are stronger predictors of MetS in this population.

\section{Conclusion}

There was no significant difference in the prevalence of MetS between patients with and without COPD. spirometry parameters and respiratory problems in subjects with and without metabolic syndrome were significance.

\section{Introduction}

Chronic obstructive pulmonary disease (COPD) is a complex respiratory disorder associated with an abnormal inflammatory response of the lungs to particles or toxic gases. COPD is the leading cause of death and disability and one of the most important health issues in Iran and around the world. It is projected that by 2030, COPD will be the third leading cause of death among all causes of death in worldwide [1]. In one meta-analysis, the global prevalence of COPD was $12.16 \%$, with the highest 
prevalence in the Americas (14.33\%) and the lowest in Southeast Asia / Western Pacific (8.80\%). Thus, this meta-analysis study shows that more than $12 \%$ of the world's population suffers from COPD [2]. In Iran, in the study of the mortality trend of COPD during 2001-2015, the total number of mortality from COPD was 8,832, and age-standardized COPD mortality rates in males and females, respectively, were 12.38 (9.815.6) and $8.46(6.6-10.9)$ [3]. The overall prevalence of COPD in 5 provinces of different parts of Iran was $4.9 \%$ [4], and in estimating the burden of obstructive pulmonary disease in Iran was 8.3\% [5].

Although COPD is initially characterized by inflammation and obstruction of the pulmonary airflow, its effects go far beyond the lungs, and a broader definition has been proposed for COPD as a systemic inflammatory syndrome [6]. Comorbidities are common in patients with COPD including metabolic syndrome (MetS) that is a complex disorder of cardiovascular risk factors for COPD [7]. MetS is known as a coexist with COPD [8]. Systemic inflammation plays a key role in COPD and MetS, but the true inflammatory characteristics of these patients are still unknown [9].

MetS is a common medical disease and the leading cause of death worldwide [10] and includes a number of risk factors for cardiovascular disease, including insulin resistance, hypertension, dyslipidemia, and abnormal body fat distribution [11]. MetS is not specifically symptomatic, but other MetS disorders can be diagnosed based on one or two of these factors. The results of various studies have shown that the prevalence of the MetS is higher in patients with COPD than in the general population and almost half of the patients with COPD have one or more MetS components [12-14]. MetS in COPD is also associated with a higher risk of CVD, and these patients may die from CVD before reaching the final stage of COPD. Evaluation of the prevalence of MetS and its components serves as a cornerstone of the prevention of increased Cardiometabolic risk in COPD patients and allows us to specifically target these risk factors [9]. This study aimed to determine the prevalence of MetS and its components in patients with COPD compared with people without COPD in a population-based cohort study.

\section{Methods}

The current study used the data of the Shahrekord Cohort Study (SCS) with a population-based crosssectional design in the baseline recruitment phase. SCS is a part of the Prospective Epidemiological Research Studies in IrAN (PERSIAN) cohort with a sample size of 10075 in Shahrekord, Iran. This study was performed on 6961 people who participated in the COPD cohort study and had complete data for the variables of pulmonary function test (PFT) parameters were used. COPD cohort study is one of the sub cohorts of SCS. Details of the protocol and the objectives of the sub cohorts COPD study, sample size, laboratory measurements, instrument, and physical examinations have already been published $[15,16]$. Data collection was carried out according to the cohort protocol from 2015-2019 [17]. This national study is designed to investigate the health of the population and reduce the causes and risk factors for chronic diseases and improve the healthy lifestyle in Chaharmahal and Bakhtiari province, southwestern Iran, which was launched in November 2015. The main details of the study's protocol have already been published [18].

\section{Demographic and Clinical Characteristics}


Complete information on demographic characteristics such as age, sex, education level, marital status, time at beginning of smoking, drug use, respiratory symptoms (such as shortness of breath, cough, sputum, and wheezing) was collected through a questionnaire.

Spirometry parameters were collected using spirometry. Portable Spirometer (MIR, Italy, 2015) was used to evaluate pulmonary function. PFTs were performed based on the American Thoracic Society guidelines in a sitting position on comfortable chairs using a nasal clip. These tests were performed three times on each person in an acceptable manner and bronchodilator by trained technicians. Spirometry was not performed in individuals with a history of heart attack and stroke, pulmonary embolism, uncontrolled blood pressure of more than $120 / 200$, and recent eye, ear, brain surgery, recent abdominal or thoracic surgery, and abdominal or thoracic aortic aneurysm.

\section{Definition of COPD disease}

COPD was defined as the fixed ratio of forced expiratory volume in one second (FEV1) over forced vital capacity (FVC) less than 0.7 (FEV1/FVC $<70 \%$ ) according to the Global Initiative for Obstructive Lung Disease (GOLD) guidelines [1]. The post-bronchodilator spirometry was carried out for patients with a prebronchodilator $\mathrm{FEV} 1 / \mathrm{FVC}$ ratio $<80 \%$ or an $\mathrm{FVC}<80 \%$ and 15 minutes after administration of 2 puffs of salbutamol $(200 \mu \mathrm{g})$ via a spacer standard to evaluate the reversibility of the obstruction. We used a prebronchodilator FEV1/FVC ratio $<0.8$ or an $\mathrm{FVC}<80 \%$ as cutoffs for whether or not to do post-bronchodilator spirometry, to avoid underestimating FVC, which could result in a normal FEV1/FVC ratio. COPD was defined as the presence of post-bronchodilator FEV1/FVC of less than 70\%. The PFT parameters values were presented as the percent of predicted values for the respective height, weight, age, and sex. The predicted FVC\% (FVC [\%]), predicted FEV1\% (FEV1 [\%]), predicted PEF\% (PEF [\%]), predicted FEV6\% (FEV6 [\%]) were calculated by dividing the FVC (L), FEV1 (L), PEF (L), FEV6 (L) by the predicted FVC, FEV1, PEF, FEV6 respectively. When PFT parameters are presented as \% predicted, this means that pulmonary function is given as a percentage of the normal value as expected for healthy people of the same sex, age, and height according to local references [19]. The severity of COPD was determined by the GOLD guidelines as follows: GOLD I (mild): FEV1/FVC $<70 \%$ and FEV1 $\geq 80 \%$ predicted; GOLD II (moderate): FEV1/FVC $<70 \%$ and FEV1 50-79\% predicted; GOLD III (Severe): FEV1/FVC < 70\% and FEV1 30-49\% predicted; and GOLD IV (Very severe): FEV1/FVC $<70 \%$ and FEV1 $<30 \%$ [20].

\section{Metabolic Syndrome}

To determine whether participants have MetS, systolic blood pressure (SBP), diastolic blood pressure (DBP), abdominal obesity (waist circumference (WC)), fasting blood sugar (FBS), triglycerides (TG), and high density lipoprotein cholesterol (HDL-c) were measured. Weight was measured using a Secca digital scale with minimal clothes and no shoes. Height, and WC were measured using a tape measure to the nearest $1 \mathrm{~cm}$. Body mass index (BMI) (weight (kg) per height squared (m2)) was measured in each participant. To measure blood pressure, the subjects were asked to rest for 15 minutes. Then the blood pressure was measured in the sitting position on the right arm three times with intervals of at least 5 minutes using the Riester digital pressure gauge (ri-champion). The mean of the three measurements was 
then calculated as the final blood pressure of the individuals. High blood pressure (HBP) was defined by the Joint National Committee VI (JNCVI) criteria as SBP $\geq 140 \mathrm{mmHg}$ or DBP $\geq 90 \mathrm{mmHg}$ or taking hypoglycemic drugs [21]. For blood lipid tests, including low density lipoprotein cholesterol (LDL), HDL-C, total cholesterol ( $\mathrm{CHO}$ ), triglyceride (TG), and FBS, a venous blood sample was collected from all subjects after 8-12 hours of fasting between 7 to 9 in the morning in the laboratory of Shahrekord Cohort Study. The MetS variable was defined according to Adult Treatment Panel III criteria and included those with at least three of the following disorders: FBS equal to or greater than $100 \mathrm{mg} / \mathrm{dM}$, TG equal to or greater than $150 \mathrm{mg} / \mathrm{dL}, \mathrm{HDL}-\mathrm{c}$ equal to or less than 50 and $40 \mathrm{mg} / \mathrm{dM}$ in men and women, respectively, SBP equal to or higher than $135 \mathrm{~mm} \mathrm{Hg}$ and DBP greater than 85, WC greater than 88 and $102 \mathrm{~cm}$ in men and women, respectively, and MetS variables were considered after coding two groups with MetS and non- MetS [22].

\section{Statistical analysis}

Data were analyzed using two-independent sample t-tests, chi-square test, and logistic regression model. The results were presented as mean and standard deviation for quantitative variables and as frequency (percentage) for categorical variables and odds ratio (OR) with 95\% confidence interval (Cl 95\%) in logistic regression models. To compare the relationship between MetS and its components in two groups of COPD patients and without COPD, two-independent sample t-tests, and chi-square test was used. A univariable and multivariable logistic regression model was conducted to determine the risk of having MetS and sociodemographic predictors. All analyses were conducted using stata statistical software: release 16 (stata Corp, College Station, Texas 77845 USA).

\section{Result}

In our study, out of 6961 participants, $2152(30.9 \%)$ had MetS. The mean age of MetS patients was $51.64 \pm$ 9.16. The highest prevalence MetS was observed in the age group above 55 years (39.1\%), women (52.9\%), low level of education (49.6\%), living in urban areas (86.8\%), and those with BMI over 25 (91.3\%).

The mean age of patients $(52.50 \pm 9.76)$ was significantly higher than that of those without COPD (49.34 \pm 9.26). $55.8 \%$ (n: 120) were male and $44.2 \%$ (n: 95) were female. The mean SBP and DBP, and WC was significantly higher in people with COPD than in those without COPD $(P<0.05)$. However, there was no significant difference in the mean FBS level, HDL-c, TG levels, and BMI between individuals with and without COPD $(P<0.05)($ Table 1$)$.

In the present study, the prevalence of MetS in patients with COPD was $28.4 \%$ and in people without COPD was $31 \%$. There was no significant difference between the prevalence of MetS in general and also by gender.

The most common component of MetS in people with COPD was low HDL-c (47.4\%), high WC (43.9\%), and High FBS (39.3\%). In male patients, the most common component was low HDL-c (61.2\%), high TG (47.4\%), high FBS (41.4\%), and in female patients, high WC (69.5\%), high FBS (38.8\%), and low HDL-c (30.5\%). 
HBP levels and high FBS levels were significantly higher in patients than in healthy individuals $(P<0.05)$, but these differences were not significant when analyzed by gender.

There was no significant difference between low HDL-c levels between patients and healthy people, but when analyzed by gender, this difference was significant in women, so that in women patients, low HDL-c levels were significantly higher than healthy women.

There was no statistically significant difference between other MetS parameters between individuals with and without COPD. $30.2 \%(65)$ of patients (28.3\% in males and $32.6 \%$ in females) had at least one MetS parameter (Table 2).

In the present study, the mean PFT parameters were significantly lower in patients than in healthy individuals, However, there was no significant difference in the \% predicted values of PFT parameters among individuals with and without MetS (Table 3).

In this study, there was a statistically significant difference in the frequency of respiratory problems and history of chronic lung disease (asthma, tuberculosis, emphysema, and bronchitis) between people with and without MetS $(P<0.05)$ (Table 3$)$.

MetS frequencies in patients with stages GOLD I, II, III and IV were 31 (50.8 \%), 24 (39.3\%), 6 (9.8 \%) and 0 $(0 \%)$, respectively (Table 4$)$.

The logistic regression analysis showed that age above 60 years old compared to the age of 35-44 years $(\mathrm{OR}=2.20,95 \% \mathrm{Cl}: 1.72-2.80)$, Gender of woman compared to men (OR $=1.71,95 \% \mathrm{Cl}: 1.49-1.97)$, The level of illiterate education compared to the level of university education $(\mathrm{OR}=1.80,95 \% \mathrm{Cl}$ : 1.49-2.17), living in urban area (compared to living in rural area and obese compared to underweight and normal (OR = $2.43,95 \% \mathrm{Cl}: 2.06-2.88$ ) are stronger predictors of MetS in this population (Table 5).

\section{Discussion}

MetS is a common medical condition and one of the common comorbidities of COPD. There is ample epidemiological and clinical evidence to support an important association between pulmonary dysfunction and MetS, but the exact nature of this association is still unknown and further studies are needed. Therefore, this study aimed to determine the prevalence of MetS in COPD patients in comparison with NonCOPD individuals in a population aged 35-75 years from Shahrekord Cohort Study.

In our study, out of 6961 participants, 30.9\% had MetS. The highest prevalence MetS was observed in the age group above 55 years, women, low level of education, living in urban areas, and those with BMI over 25.

In the present study, the mean age of COPD patients was significantly higher than those without COPD. Most patients were male (55.8\%). In this study, there was no significant difference between the mean components of MetS with the exception of SBP, DBP, WC in individuals with and without COPD. The prevalence of MetS in patients with COPD was $28.4 \%$. The difference in the prevalence of MetS between patients with and without COPD was small. In fact, we did not see a statistically significant difference in the 
prevalence of MetS in people with COPD without COPD. This may be because the general population includes people without COPD but with other comorbidities. In the study of Choi et al., among 2164 patients with COPD in Korea in 2007-2012, the prevalence of MetS was $31.2 \%$ and was significantly higher in women than in men (35.1\% VS $26.6 \%$ ) [23]. In one meta-analysis study of 4,208 patients with COPD from 19 studies, the pooled Prevalence of MetS in patients was $34 \%$, and significantly higher than that in the control group (32\% vs. $30 \%$ ). Hypertension, abdominal obesity, and hyperglycemia were the most common parameters of MetS in patients in this meta-analysis [24]. Verma et al. reported the prevalence of MetS in COPD patients as $15.7 \%$ [25].

In this study, MetS parameters were examined one by one. There was no statistically significant difference in the components of MetS except for HBP and high FBS between two groups of people with and without COPD. HBP levels and high FBS were significantly higher in patients than in healthy individuals $(P<0.05)$, but these differences were not significant when analyzed by gender. There was no significant difference between low HDL-c levels between patients and healthy people, but when analyzed by gender, this difference was significant in women, so that in women patients, low HDL-c levels were significantly higher than healthy women. The most common component of MetS in people with COPD was low HDL-C, WC, and High FBS. In male patients, the most common component was low HDL-c, high TG, and high FBS, and in female patients, WC, high FBS, and low HDL-c was the most common MetS component. In general, the prevalence of MetS components in people without COPD was higher than in people with COPD, which is why the prevalence of MetS in COPD patients was lower than in people without COPD (28.4\% VS 31\%), which was inconsistent with the results of other studies. In the study of Bermudez et al. in Philippines in 2017-2018, consistent with our findings, MetS was not associated with airflow obstruction, and among the MetS components, only HBP was associated with airflow obstruction [26]. In a case-control study conducted by Singh et al at the chest clinic of a tertiary teaching care teaching hospital in North India in 2018 , the prevalence of MetS was significantly higher in COPD patients (49.3\%) than in control subjects (29.9\%), which was not consistent with the results of our study. In this study, in analyzing the relationship between individual components of MetS, the authors found that serum TG, SBP, and DBP were significantly higher in COPD than in apparently healthy individuals; however, HDL-c was significantly lower in COPD patients than in the control group, which is highly consistent with our study results [27]. A case study by Naseem et al in 2019 in northern India showed that MetS was common comorbidity, especially in mild to moderate forms of COPD. Among the components of MetS, WC, FBS, high TG levels, SBP and DBP were significantly higher in patients with MetS $(P<0.001)$ [28]. In prospective study by El-toney and colleagues on 70 patients with stable COPD at the chest clinic of Cardiothoracic Minia University Hospital during 2016-2016, 44\% of patients with COPD had MetS. In this study, DBP, TG, and FBS were significantly higher in patients with COPD with MetS than in patients without MetS, while HDL-c was significantly higher in patients with COPD without MetS [29].

In this study, we did not observe statistically significant differences in the prevalence of MetS in different stages of GOLD, which was similar to the results of other studies $[7,14,25]$. The frequency of MetS based on GOLD (IIV) stages was 31 (50.8\%), 24 (39.3\%), 6 (9.8\%) and 0.0\%, respectively. The results of an cross- 
sectional study in southern India in 2020 showed that $54 \%$ of patients with COPD, especially in stage II and III, have MetS [30].

In our study, there was a statistically significant difference between respiratory symptoms and MetS. In cross-sectional study of Park and Larson in the United States in 2007-2010, respiratory symptoms were significantly higher in people with MetS than in those without MetS, which was consistent with the results of our study [31]. Diez-Manglano et al. reported in a cross-sectional, multicenter study in 2014 that people with MetS have more shortness of breath than people without MetS [32]. In the present study, the mean pulmonary function parameters were significantly lower in patients than in healthy individuals, However, there was no significant difference in the \% predicted values of lung function test parameters among individuals with and without MetS. There was no statistically significant relationship between spirometry parameters and MetS in Park and Larson study. [31]. Several studies have reported that people with MetS are more likely to have milder COPD and better FEV1 [14, 31, 32].

The results of multiple logistic regression analysis showed that older age, female gender, low level of education, urbanization, overweight and obesity are the most important predictors of MetS that were consistent with the results of other studies in Iran and other countries [33-37].

One of the strengths of our study is the use of a population sample with a sufficient sample size that can be a good representative of our study population and this increases the generalizability of the findings of this study. One of the main limitations of the cross-sectional study is that it does not allow causal conclusions, and prospective studies are needed to better understand the role of metabolic syndrome and its components in the development of COPD.

\section{Conclusion}

There was no significant difference in the prevalence of MetS between patients with and without COPD. spirometry parameters and respiratory problems in subjects with and without MetS were significance. The most common component of MetS in people with COPD was low HDL-c, WC, and high FBS. Various epidemiological studies have shown the concomitance of MetS and components with COPD. Although it is not clear how MetS and its components develop in people with COPD, however optimizing each of the MetS components or parameters is a sensible way to minimize the risk of respiratory comorbidities and COPD and it is also advisable to do more to reduce MetS parameters in society, especially in those with COPD, to reduce disease progression. In primary care, we should consider MetS in patients with COPD and control and manage them well to reduce the risk of common comorbidities such as cardiovascular disease as well as mortality and disability.

\section{Declarations}

Competing interests: The authors declare that they have no competing interests.

Ethics approval and consent to participate: This study was conducted with observance of the Declaration of Helsinki and the National Ethical Guidelines in Biomedical Research in Iran. As well, the study protocol 
was approved by the Ethics Committee of the SKUMS (IR.SKUMS.REC 1394.286 and IR. SKUMS.1396.110) at regional and national scales. All participants provided signed and fingerprinted informed written consent according to the Guidelines enforced by the Ethics Committee of the SKUMS. The participants can withdraw from the study whenever they wish. Data are stored in a codified confidential database.

Funding: The SCS was funded by Iran's Ministry of Health and Medical Education (number 700/120), to develop cohort studies across Iran, and financially and non-financially supported by the SKUMS (number 2763 and 3366).

Availability of data and material: The study that is ongoing. The general information is available from: http://cohort.skums.ac.ir. All researchers across Iran and the world can have free access to the findings of this study, and necessary processes are available at the Cohort website to reproduce the research project, participate in collaborative research projects, and use the data. After requested, under conditions of collaboration and endowment, Access to the data is available for interest researchers from corresponding author in AA (aliahmadi2007@gmail.com).

Consent for publication: Not applicable.

Acknowledgements: We hereby gratefully thank all people especially the participants, the field team, the staff of the Research and Technology Deputy of the SKUMS, the Research Councils of the Faculty of Public Health, Modeling in Health Research Center, Shahrekord and Ardal health centers of the SKUMS, the Treatment, Health, and Resource and Management Deputies of the SKUMS. In addition, we thank the central quality control team of the PERSIAN Cohort for providing the Central Protocol and the checklists of making arrangements and training the interviewers and monitoring their performance as well as assisting in implementing the cohort phases, especially Hossein Poustchi, Hamid Rouhi, Reza Gojani, Kamal Solati, Arsalan Khaledifar and Morteza Hashemzadeh.

\section{References}

1. Vogelmeier CF, Criner GJ, Martinez FJ, Anzueto A, Barnes PJ, Bourbeau J, et al. GOLD executive summary. Am J Respir Crit Care Med. 2017;195(5):557-582. doi: 10.1164/rccm.201701-0218PP. [PubMed PMID: 28128970].

2. Varmaghani M, Dehghani M, Heidari E, Sharifi F, Moghaddam SS, Farzadfar F. Global prevalence of chronic obstructive pulmonary disease: systematic review and meta-analysis. East Mediterr Health J. 2019;25(1):47-57. doi: 10.26719/emhj.18.014. [PubMed PMID: 30919925].

3. Varmaghani M, Kebriaeezadeh A, Sharifi F, Sheidaei A, Rashidian A, Moradi-Lakeh M, et al. Deathspecific rate due to asthma and chronic obstructive pulmonary disease in Iran. Clin Respir $\mathrm{J}$. 2018;12(6):2075-2083. doi: 10.1111/crj.12776. [PubMed PMID: 29405628].

4. Sharifi $\mathrm{H}$, Ghanei M, Jamaati $\mathrm{H}$, Masjedi MR, Aarabi M, Sharifpour A, et al. Burden of Obstructive Lung Disease study in Iran: First report of the prevalence and risk factors of COPD in five provinces. Lung India. 2019;36(1):14. doi: 10.4103/lungindia.lungindia_129_18. [PubMed PMID: 30604700 PMCID: PMC6330801]. 
5. Sharifi H, Ghanei M, Jamaati H, Masjedi MR, Aarabi M, Sharifpour A, et al. Burden of obstructive lung disease in Iran: Prevalence and risk factors for COPD in North of Iran. Int J Prev Med. 2020;11(78). doi: 10.4103/ijpvm.IJPVM_478_18. [PubMed PMID: 33033587 PMCID: PMC7513778].

6. Fabbri LM, Rabe KF.F From COPD to chronic systemic inflammatory syndrome? The Lancet. 2007;370(9589):797-799. doi: 10.1016/S0140-6736(07)61383-X. [PubMed PMID: 17765529].

7. Breyer M-K, Spruit MA, Hanson CK, Franssen FM, Vanfleteren LE, Groenen MT, et al. Prevalence of metabolic syndrome in COPD patients and its consequences. PloS one. 2014;9(6):e98013. doi: 10.1371/journal.pone.0098013. [PubMed PMID: 24950070 PMCID: PMC4064974].

8. Clini E, Crisafulli E, Radaeli A, Malerba M. . COPD and the metabolic syndrome: an intriguing association. Intern Emerg Med. 2013;8(4):283-289. doi: 10.1007/s11739-011-0700-x. [PubMed PMID: 21964838].

9. Akpinar EE, Akpinar S, Ertek S, Sayin E, Gulhan M. Systemic inflammation and metabolic syndrome in stable COPD patients. Tuberk Toraks. 2012;60(3):230-237. [PubMed PMID: 23030748].

10. Mirrakhimov AE. Chronic obstructive pulmonary disease and glucose metabolism: a bitter sweet symphony. Cardiovasc Diabetol. 2012;11(1):132.doi: 10.1186/1475-2840-11-132. [PubMed PMID: 23101436 PMCID: PMC3499352].

11. Chiti H, Hoseinpanah F, Mehrabi Y, Azizi F. The prevalence of metabolic syndrome in adolescents with varying degrees of body weight: Tehran lipid and glucose study (TLGS). Iran J Endocrinol Metab. 2009;11(6):625-637.

12. Funakoshi Y, Omori H, Mihara S, Marubayashi T, Katoh T. Association between airflow obstruction and the metabolic syndrome or its components in Japanese men. Intern Med J. 2010;49(19):2093-2099. doi: 10.2169/internalmedicine.49.3882. [PubMed PMID: 20930435].

13. Marquis K, Maltais F, Duguay V, Bezeau A-M, LeBlanc P, Jobin J, et al. The metabolic syndrome in patients with chronic obstructive pulmonary disease. J Cardiopulm Rehabil Prev. 2005;25(4):226-232. doi: 10.1097/00008483-200507000-00010.

14. Vujic T, Nagorni O, Maric G, Popovic L, Jankovic J. Metabolic syndrome in patients with chronic obstructive pulmonary disease: frequency and relationship with systemic inflammation. Hippokratia. 2016;20(2):110. [PubMed PMID: 28416906 PMCID: PMC5388510].

15. Kiani FZ, Ahmadi A. Prevalence of different comorbidities in chronic obstructive pulmonary disease among Shahrekord cohort study in southwest Iran. Sci Rep. 2020. Doi: 10.1038/s41598-020-79707-y.

16. Kiani FZ, Ahmadi A, Soleymani Babadi A, Rouhi H. Profile and preliminary results of Iranian sub cohort chronic obstructive pulmonary disease (COPD) in Shahrekord PERSIAN cohort in southwest Iran. BMC Pulm Med. 2021;21(1):105. doi: 10.1186/s12890-021-01469-8. [PubMed PMID: 33765987 PMCID: PMC7993468].

17. Poustchi H, Eghtesad S, Kamangar F, Etemadi A, Keshtkar A-A, Hekmatdoost A, et al. Prospective epidemiological research studies in Iran (the PERSIAN Cohort Study): rationale, objectives, and design. Am J Epidemiol. 2018;187(4):647-655. doi: 10.1093/aje/kwx314. [PubMed PMID: 29145581 PMCID: PMC6279089]. 
18. Khaledifar A, Hashemzadeh M, Solati K, Poustchi H, Bollati V, Ahmadi A, et al. The protocol of a population-based prospective cohort study in southwest of Iran to analyze common noncommunicable diseases: Shahrekord cohort study. BMC public health. 2018;18(1):660. doi: 10.1186/s12889-018-5364-2. [PubMed PMID: 29801446 PMCID: PMC5970455].

19. Pellegrino R, Viegi G, Brusasco V, Crapo R, Burgos F, Casaburi R, et al. Interpretative strategies for lung function tests. Eur Respir J. 2005;26(5):948-968. doi: 10.1183/09031936.05.00035205. [PubMed PMID: 16264058].

20. Vestbo J, Hurd SS, Agustí AG, Jones PW, Vogelmeier C, Anzueto A, et al. Global strategy for the diagnosis, management, and prevention of chronic obstructive pulmonary disease: GOLD executive summary. Am J Respir Crit Care Med. 2013;187(4):347-365. doi: 10.1164/rccm.201204-0596PP. [PubMed PMID: 22878278].

21. Martin J. Hypertension guidelines: revisiting the JNC 7 recommendations. JLGH. 2008;3(3).

22. Grundy SM, Brewer Jr HB, Cleeman JI, Smith Jr SC, Lenfant C. Definition of metabolic syndrome: report of the National Heart, Lung, and Blood Institute/American Heart Association conference on scientific issues related to definition. Circulation. 2004;109(3):433-438.

https://doi.org/10.1161/01.CIR.0000111245.75752.C6. [PubMed PMID: 14766739].

23. Choi HS, Rhee CK, Park YB, Yoo KH, Lim SY. Metabolic Syndrome in Early Chronic Obstructive Pulmonary Disease: Gender Differences and Impact on Exacerbation and Medical Costs. Int J Chron Obstruct Pulmon Dis. 2019;14:2873. doi: 10.2147/COPD.S228497. [PubMed PMID: 31849460 PMCID: PMC6911318].

24. Cebron Lipovec N, Beijers RJ, van den Borst B, Doehner W, Lainscak M, Schols AM. The prevalence of metabolic syndrome in chronic obstructive pulmonary disease: a systematic review. COPD: Journal of Chronic Obstructive Pulmonary Disease. 2016;13(3):399-406. doi: 10.3109/15412555.2016.1140732. [PubMed PMID: 26914392].

25. Verma S, Jamsheer A, Surya Kant K, RAS RG, Santosh Kumar AS, Bajajand D. Prevalence of metabolic syndrome in chronic obstructive pulmonary disease patients". IJCRLS. 2018;7(02):1144-1147. Available online at http://www.ijcrls.com

26. Bermudez G, Jasul Jr G, David-Wang A, Jimeno C, Magallanes J, Macalalad-Josue AA. Association of Metabolic Syndrome with the Severity of Airflow Obstruction in Patients with Chronic Obstructive Pulmonary Disease. J ASEAN Fed Endocr Soc. 2018;33(2):181. doi: 10.15605/jafes.033.02.11. [PubMed PMID: 33442125 PMCID: PMC7784159].

27. Singh A, Singla M, Soni R. METABOLIC SYNDROME IN STABLE COPD PATIENTS AMONGST NORTH INDIAN POPULATION: A CASE CONTROL STUDY. Int J Sci Res. 2018;7(2).

28. Naseem S, Baneen U. Systemic inflammation in patients of chronic obstructive pulmonary disease with metabolic syndrome. J Family Med Prim Care. 2019;8(10):3393. doi: 10.4103/jfmpc.jfmpc_482_19. [PubMed PMID: 31742175 PMCID: PMC6857392].

29. El-toney AFS, Mohamed BI, Abd-Elnaeem EA, Ismail AS. Metabolic syndrome; frequency and its relationship with variable parameters in chronic obstructive pulmonary disease. Egypt J Bronchol. 2019;13(2):148. doi: 10.4103/ejb.ejb_51_18. 
30. Priyadharshini N, Renusha R, Reshma S, Sai MS, Muthu RMK, Rajanandh M. Prevalence of metabolic syndrome in patients with chronic obstructive pulmonary disease: An observational study in South Indians. Diabetes Metab Syndr. 2020. doi: 10.1016/j.dsx.2020.04.042. [PubMed PMID: 32388329].

31. Park SK, Larson JL. Metabolic syndrome and associated factors in people with chronic obstructive pulmonary disease. West J Nurs Res. 2014;36(5):620-642. doi: 10.1177/0193945913512423. [PubMed PMID: 24292806 PMCID: PMC4031648].

32. Diez-Manglano J, Barquero-Romero J, Almagro P, Cabrera FJ, García FL, Montero L, et al. COPD patients with and without metabolic syndrome: clinical and functional differences. Intern Emerg Med. 2014;9(4):419-425. doi: 10.1007/s11739-013-0945-7. [PubMed PMID: 23645508].

33. Xi B, He D, Hu Y, Zhou D. Prevalence of metabolic syndrome and its influencing factors among the Chinese adults: the China Health and Nutrition Survey in 2009. Prev Med. 2013;57(6):867-871. doi: 10.1016/j.ypmed.2013.09.023. [PubMed PMID: 24103567 PMCID: PMC4044099].

34. Syed MA, Al Nuaimi AS, Latif Zainel AJA, A/Qotba HA. Prevalence of metabolic syndrome in primary health settings in Qatar: a cross sectional study. BMC Public Health. 2020;20:1-7. https://doi.org/10.1186/s12889-020-08609-5. [PubMed PMID: 32362284 PMCID: PMC7196222].

35. Higuita-Gutiérrez LF, Quiroz WdJM, Cardona-Arias JA. Prevalence of Metabolic Syndrome and Its Association with Sociodemographic Characteristics in Participants of a Public Chronic Disease Control Program in Medellin, Colombia, in 2018. Diabetes Metab Syndr Obes: Targets Ther. 2020;13:1161. doi: 10.2147/DMSO.S242826. [PubMed PMID: 32346303 PMCID: PMC7169935].

36. Jahangiry L, Khosravi-far L, Sarbakhsh P, Kousha A, EntezarMahdi R, Ponnet K. Prevalence of metabolic syndrome and its determinants among Iranian adults: evidence of IraPEN survey on a biethnic population. Sci Rep. 2019;9(1):1-7. doi: 10.1038/s41598-019-44486-8. [PubMed PMID: 31138853 PMCID: PMC6538652].

37. Nikbakht H-A, Rezaianzadeh A, Seif M, Ghaem H. Prevalence of metabolic syndrome and its components among a population-based study in south of Iran, PERSIAN Kharameh cohort study. Clin Epidemiol Glob Health. 2020. https://doi.org/10.1016/j.cegh.2020.01.001.

\section{Tables}


Table 1

Baseline Characteristics of Sub Cohort COPD

\begin{tabular}{|c|c|c|c|}
\hline Variable & COPD & Non-COPD & $P$ \\
\hline Mean age $(y)$ & $52.50 \pm 9.76$ & $49.34 \pm 9.26$ & $<0.0001^{\star}$ \\
\hline Male- N (\%) & $120(55.8 \%)$ & $3179(47.1 \%)$ & \multirow[t]{2}{*}{$0.012^{\star \star}$} \\
\hline Female- N (\%) & $95(44.2 \%)$ & $3567(52.9 \%)$ & \\
\hline FBS (mg/dl) & $101.56 \pm 31.41$ & $98.37 \pm 27.97$ & $0.104^{\star}$ \\
\hline $\mathrm{HDL}(\mathrm{mg} / \mathrm{dl})$ & $51.55 \pm 11.75$ & $51.06 \pm 11.65$ & $0.551^{\star}$ \\
\hline TG (mg/dl) & $148.53 \pm 67.97$ & $153.24 \pm 80.314$ & $0.4^{\star}$ \\
\hline $\mathrm{SBP}(\mathrm{mm} \mathrm{Hg})$ & $117.8 \pm 16.19$ & $115.07 \pm 16.29$ & $0.013^{\star}$ \\
\hline DBP (mm Hg) & $77.49 \pm 9.67$ & $75.45 \pm 10.45$ & $0.005^{\star}$ \\
\hline Waist circumference $(\mathrm{cm})$ & $96.10 \pm 12.11$ & $94.37 \pm 11.17$ & $0.026^{\star}$ \\
\hline BMI (kg/m2) & $28.12 \pm 4.69$ & $27.74 \pm 4.58$ & $0.225^{\star}$ \\
\hline
\end{tabular}


Table 2

Frequency Metabolic Syndrome, comparison* and each metabolic component in men and women

\begin{tabular}{|c|c|c|c|c|c|c|c|c|c|}
\hline \multirow{3}{*}{$\begin{array}{l}\text { Metabolic } \\
\text { component }\end{array}$} & \multicolumn{3}{|l|}{ Total } & \multicolumn{3}{|l|}{ Men } & \multicolumn{3}{|l|}{ Women } \\
\hline & & $\begin{array}{l}\text { Non- } \\
\text { COPD }\end{array}$ & $\begin{array}{l}P \\
\text { value }\end{array}$ & & $\begin{array}{l}\text { Non- } \\
\text { COPD }\end{array}$ & $\begin{array}{l}P \\
\text { value }\end{array}$ & & $\begin{array}{l}\text { Non- } \\
\text { COPD }\end{array}$ & $\begin{array}{l}\mathrm{P} \\
\text { value }\end{array}$ \\
\hline & $\begin{array}{l}N= \\
215\end{array}$ & $\begin{array}{l}N= \\
6746\end{array}$ & & $\mathbf{N}=120$ & $\begin{array}{l}\mathrm{N}= \\
3179\end{array}$ & & $N=95$ & $\begin{array}{l}N= \\
3567\end{array}$ & \\
\hline \multirow{2}{*}{$\begin{array}{l}\text { Metabolic } \\
\text { Syndrome }\end{array}$} & 61 & 2091 & \multirow[t]{2}{*}{0.229} & \multirow{2}{*}{$\begin{array}{l}35 \\
(29.2 \%)\end{array}$} & 979 & \multirow[t]{2}{*}{0.395} & 26 & \multirow{2}{*}{$\begin{array}{l}1112 \\
(31.2 \\
\%)\end{array}$} & \multirow[t]{2}{*}{0.251} \\
\hline & $\begin{array}{l}(28.4 \\
\%)\end{array}$ & $\begin{array}{l}(31 \\
\%)\end{array}$ & & & $\begin{array}{l}(30.8 \\
\%)\end{array}$ & & $\begin{array}{l}(27.4 \\
\%)\end{array}$ & & \\
\hline \multirow{2}{*}{$\begin{array}{l}\text { Abdominal } \\
\text { obesity (waist } \\
\text { circumference) }\end{array}$} & 94 & \multirow{2}{*}{$\begin{array}{l}3252 \\
(48.2 \\
\%)\end{array}$} & \multirow[t]{2}{*}{0.121} & 28 & 673 & \multirow[t]{2}{*}{0.304} & 66 & \multirow{2}{*}{$\begin{array}{l}2579 \\
(72.3 \\
\%)\end{array}$} & \multirow[t]{2}{*}{0.307} \\
\hline & $\begin{array}{l}(43.9 \\
\%)\end{array}$ & & & $\begin{array}{l}(23.5 \\
\%)\end{array}$ & $\begin{array}{l}(21.2 \\
\%)\end{array}$ & & $\begin{array}{l}(69.5 \\
\%)\end{array}$ & & \\
\hline \multirow{2}{*}{$\begin{array}{l}\text { High blood } \\
\text { pressure }\end{array}$} & 57 & \multirow{2}{*}{$\begin{array}{l}1429 \\
(21.2 \\
\%)\end{array}$} & \multirow[t]{2}{*}{0.039} & 39 & 830 & \multirow[t]{2}{*}{0.076} & 18 & \multirow{2}{*}{$\begin{array}{l}599 \\
(16.8 \\
\%)\end{array}$} & \multirow[t]{2}{*}{0.331} \\
\hline & $\begin{array}{l}(26.5 \\
\%)\end{array}$ & & & $\begin{array}{l}(32.5 \\
\%)\end{array}$ & $\begin{array}{l}(26.1 \\
\%)\end{array}$ & & $\begin{array}{l}(18.9 \\
\%)\end{array}$ & & \\
\hline \multirow{2}{*}{$\begin{array}{l}\text { High fasting } \\
\text { blood sugar }\end{array}$} & 83 & \multirow{2}{*}{$\begin{array}{l}2181 \\
(32.9 \\
\%)\end{array}$} & \multirow[t]{2}{*}{0.031} & 48 & \multirow{2}{*}{$\begin{array}{l}1096 \\
(35.2 \\
\%)\end{array}$} & \multirow[t]{2}{*}{0.101} & \multirow{2}{*}{$\begin{array}{l}35 \\
(36.8 \%)\end{array}$} & \multirow{2}{*}{$\begin{array}{l}1085 \\
(30.9 \\
\%)\end{array}$} & \multirow[t]{2}{*}{0.131} \\
\hline & $\begin{array}{l}(39.3 \\
\%)\end{array}$ & & & $\begin{array}{l}(41.4 \\
\%)\end{array}$ & & & & & \\
\hline \multirow{2}{*}{$\begin{array}{l}\text { High } \\
\text { triglyceride }\end{array}$} & 81 & \multirow{2}{*}{$\begin{array}{l}2765 \\
(41.7 \\
\%)\end{array}$} & \multirow[t]{2}{*}{0.188} & 55 & \multirow{2}{*}{$\begin{array}{l}1509 \\
(48.4 \\
\%)\end{array}$} & 0457 & 26 & $\begin{array}{l}1256 \\
(258\end{array}$ & 0.055 \\
\hline & $\begin{array}{l}(38.4 \\
\%)\end{array}$ & & & $\begin{array}{l}(47.4 \\
\%)\end{array}$ & & & $\begin{array}{l}(27.4 \\
\%)\end{array}$ & $\%)$ & \\
\hline Low HDL & 100 & 3456 & 0.100 & 71 & 1977 & 0.349 & 29 & 1479 & 0.015 \\
\hline & $\%)$ & $\%)$ & & $\begin{array}{l}(61.2 \\
\%)\end{array}$ & $\%)$ & & $\begin{array}{l}(30.5 \\
\%)\end{array}$ & $\%)$ & \\
\hline $\begin{array}{l}\text { Metabolic } \\
\text { score }\end{array}$ & & & & & & & & & \\
\hline 0 & 19 & 726 & 0.528 & $7(5.8$ & 364 & 0.108 & 12 & 362 & 0.485 \\
\hline & $\begin{array}{l}(8.8 \\
\%)\end{array}$ & $\%)$ & & & $\begin{array}{l}(11.5 \\
\%)\end{array}$ & & $\begin{array}{l}(12.6 \\
\%)\end{array}$ & & \\
\hline 1 & 65 & 1907 & & 34 & 932 & & 31 & 975 & \\
\hline & $\begin{array}{l}(30.2 \\
\%)\end{array}$ & $\%)$ & & $\begin{array}{l}(28.3 \\
\%)\end{array}$ & $\begin{array}{l}(29.3 \\
\%)\end{array}$ & & $\begin{array}{l}(32.6 \\
\%)\end{array}$ & & \\
\hline
\end{tabular}

COPD = chronic obstructive pulmonary disease, Metabolic score: Defined as the number of metabolic component present in ATP III criteria. $\mathrm{X}^{2}$-test* 


\begin{tabular}{|c|c|c|c|c|c|c|c|c|c|}
\hline \multirow{3}{*}{$\begin{array}{l}\text { Metabolic } \\
\text { component }\end{array}$} & \multicolumn{3}{|l|}{ Total } & \multicolumn{3}{|l|}{ Men } & \multicolumn{3}{|c|}{ Women } \\
\hline & & $\begin{array}{l}\text { Non- } \\
\text { COPD }\end{array}$ & $\begin{array}{l}P \\
\text { value }\end{array}$ & & $\begin{array}{l}\text { Non- } \\
\text { COPD }\end{array}$ & $\begin{array}{l}P \\
\text { value }\end{array}$ & COPD & $\begin{array}{l}\text { Non- } \\
\text { COPD }\end{array}$ & $\begin{array}{l}P \\
\text { value }\end{array}$ \\
\hline & $\begin{array}{l}N= \\
215\end{array}$ & $\begin{array}{l}N= \\
6746\end{array}$ & & $N=120$ & $\begin{array}{l}N= \\
3179\end{array}$ & & $N=95$ & $\begin{array}{l}\mathrm{N}= \\
3567\end{array}$ & \\
\hline \multirow[t]{2}{*}{2} & \multirow{2}{*}{$\begin{array}{l}71 \\
(33 \%)\end{array}$} & \multirow{2}{*}{$\begin{array}{l}2028 \\
(30.1 \\
\%)\end{array}$} & & 44 & 905 & & 27 & 1123 & \\
\hline & & & & $\begin{array}{l}(36.7 \\
\%)\end{array}$ & $\begin{array}{l}(28.5 \\
\%)\end{array}$ & & $\begin{array}{l}(28.4 \\
\%)\end{array}$ & $\%$ & \\
\hline \multirow[t]{2}{*}{$3-5$} & 60 & \multirow{2}{*}{$\begin{array}{l}2085 \\
(30.9 \\
\%)\end{array}$} & & 35 & 978 & & 25 & 1107 & \\
\hline & $\begin{array}{l}(27.9 \\
\%)\end{array}$ & & & $\begin{array}{l}(29.2 \\
\%)\end{array}$ & $\begin{array}{l}(30.8 \\
\%)\end{array}$ & & $\begin{array}{l}(26.3 \\
\%)\end{array}$ & (31\%) & \\
\hline
\end{tabular}


Table 3

Mean age, spirometry parameters and Frequency respiratory problems in subjects with and without metabolic syndrome

\begin{tabular}{|c|c|c|c|}
\hline Variable & $\begin{array}{l}\text { Metabolic } \\
\text { Syndrome } \\
\mathrm{N}=2152\end{array}$ & $\begin{array}{l}\text { Non } \\
\text { Metabolic } \\
\text { Syndrome } \\
\mathrm{N}=4809\end{array}$ & $P$ Value \\
\hline Age (years) & $51.64 \pm 9.16$ & $48.45 \pm 9.18$ & $<0.001^{\star}$ \\
\hline FEV1 & $2.68 \pm 0.77$ & $2.89 \pm 0.79$ & $<0.001^{\star}$ \\
\hline Predicted FEV1 (\%) & $\begin{array}{l}98.09 \pm \\
17.59\end{array}$ & $\begin{array}{l}101.92 \pm \\
17.05\end{array}$ & $0.339 *$ \\
\hline FVC & $2.93 \pm 0.84$ & $3.14 \pm 0.84$ & $<0.001^{*}$ \\
\hline Predicted FVC (\%) & $\begin{array}{l}88.17 \pm \\
15.38\end{array}$ & $88.90 \pm 17.25$ & $0.114^{\star}$ \\
\hline PEF & $4.71 \pm 2.00$ & $5.15 \pm 2.10$ & $<0.001^{*}$ \\
\hline Predicted PEF (\%) & $71.45 \pm 5.15$ & $72.76 \pm 2.41$ & $0.152^{\star}$ \\
\hline PEF25-75 & $3.37 \pm 1.21$ & $3.69 \pm 1.29$ & $<0.001^{*}$ \\
\hline Predicted PEF25-75 (\%) & $\begin{array}{l}112.92 \pm \\
31.80\end{array}$ & $\begin{array}{l}116.57 \pm \\
41.93\end{array}$ & $0.001^{*}$ \\
\hline FEV6 & $2.92 \pm 0.84$ & $3.13 \pm 0.86$ & $<0.001^{\star}$ \\
\hline Predicted FEV6 (\%) & $\begin{array}{l}87.97 \pm \\
15.26\end{array}$ & $88.77 \pm 17.16$ & $<0.001^{\star}$ \\
\hline FEV1/ FVC & $91.81 \pm 7.12$ & $92.59 \pm 7.60$ & $<0.001^{*}$ \\
\hline FEV1/FEV6 & $91.99 \pm 6.96$ & $92.70 \pm 7.48$ & $<0.001^{*}$ \\
\hline Cough n (\%) Yes & $317(14.7 \%)$ & $573(11.9 \%)$ & \multirow[t]{2}{*}{$0.001^{* *}$} \\
\hline Cough n (\%) NO & $\begin{array}{l}1835(85.3 \\
\%)\end{array}$ & $4233(88.1 \%)$ & \\
\hline Cough with sputum n (\%) Yes & $157(49.5 \%)$ & $262(45.7 \%)$ & \multirow[t]{2}{*}{$0.154 \star \star$} \\
\hline Cough with sputum n (\%) NO & $160(50.5 \%)$ & $311(54.3 \%)$ & \\
\hline Wheezing and shortness of breath $n(\%)$ Yes & $71(3.3 \%)$ & $106(2.2 \%)$ & \multirow[t]{2}{*}{$0.005^{\star \star}$} \\
\hline Wheezing and shortness of breath $n(\%)$ No & $\begin{array}{l}2081(96.7 \\
\%)\end{array}$ & $4700(97.8 \%)$ & \\
\hline
\end{tabular}

Abbreviation: FEV1: forced expiratory volume in $1 \mathrm{~s}$; FEV6: forced expiratory volume in $6 \mathrm{~s}$; FVC: forced vital capacity; PFT: pulmonary function test; PEF25-75: maximum peak expiratory flow (PEF) in $25 \%$, $50 \%$ and $75 \%$ of FVC. T-test*, $X^{2}$-test** 


\begin{tabular}{|c|c|c|c|}
\hline Variable & $\begin{array}{l}\text { Metabolic } \\
\text { Syndrome } \\
\mathrm{N}=2152\end{array}$ & $\begin{array}{l}\text { Non } \\
\text { Metabolic } \\
\text { Syndrome } \\
\mathrm{N}=4809\end{array}$ & P Value \\
\hline $\begin{array}{l}\text { Chronic lung disease (asthma, tuberculosis, } \\
\text { emphysema and bronchitis) }-\mathrm{n}(\%) \text { Yes }\end{array}$ & $114(5.3 \%)$ & $217(4.5 \%)$ & \multirow[t]{2}{*}{$0.088^{\star \star}$} \\
\hline $\begin{array}{l}\text { Chronic lung disease (asthma, tuberculosis, } \\
\text { emphysema and bronchitis) - } \mathrm{n}(\%) \text { No }\end{array}$ & $\begin{array}{l}2038(94.7 \\
\%)\end{array}$ & 4589 (95.5 \%) & \\
\hline \multicolumn{4}{|c|}{$\begin{array}{l}\text { Abbreviation: FEV1: forced expiratory volume in } 1 \mathrm{~s} \text {; FEV6: forced expiratory volume in } 6 \text { s; FVC: forced } \\
\text { vital capacity; PFT: pulmonary function test; PEF25-75: maximum peak expiratory flow (PEF) in } 25 \% \text {, } \\
50 \% \text { and } 75 \% \text { of FVC. T-test*, } \mathrm{X}^{2} \text {-test**}\end{array}$} \\
\hline
\end{tabular}

\section{Table 4}

Prevalence of metabolic syndrome in different Stages of GOLD

\begin{tabular}{|c|c|c|c|}
\hline $\begin{array}{l}\text { Stage-GOLD } \\
\mathrm{N}=\mathbf{2 1 5}\end{array}$ & metabolic syndrome & Non- Metabolic Syndrome & $\mathbf{P}$ \\
\hline GOLD I $(\mathrm{N}=102)$ & $31(50.80 \%)$ & $71(46.10 \%)$ & 0.530 \\
\hline GOLD \| $(N=86)$ & $24(39.30 \%)$ & $62(40.30 \%)$ & \\
\hline GOLD III (N = 22) & $6(9.80 \%)$ & $16(10.40 \%)$ & \\
\hline $\begin{array}{l}\text { GOLD IV } \\
(\mathrm{N}=5)\end{array}$ & $0(0 \%)$ & $5(3.20 \%)$ & \\
\hline
\end{tabular}


Table 5

A univariable and multivariable logistic regression model with the risk of having metabolic syndrome and socio-demographic predictors

\begin{tabular}{|c|c|c|c|c|c|c|}
\hline Variables & Crude-OR & Cl $95 \%$ & P-value & Adjusted OR & Cl $95 \%$ & P-value \\
\hline COPD & $1^{*}$ & - & - & - & - & - \\
\hline \multicolumn{7}{|l|}{ Non- COPD } \\
\hline Having COPD & 1.24 & $0.73-2.10$ & 0.417 & 1.40 & $0.81-2.41$ & 0.219 \\
\hline \multicolumn{7}{|l|}{ Age (years) } \\
\hline $35-44$ years old & 1 & - & - & - & - & - \\
\hline $45-54$ years old & 1.73 & $1.51-1.98$ & $<0.001$ & 1.59 & $1.37-1.84$ & $<0.001$ \\
\hline 55-64 years old & 2.21 & $1.91-2.55$ & $<0.001$ & 1.91 & $1.61-2.25$ & $<0.001$ \\
\hline $60+$ years old & 2.69 & $2.18-3.32$ & $<0.001$ & 2.20 & $1.72-2.80$ & $<0.001$ \\
\hline \multicolumn{7}{|l|}{ Gender } \\
\hline Men & 1 & - & - & - & - & - \\
\hline Women & 1.71 & $1.54-1.91$ & $<0.001$ & 1.36 & $1.49-1.97$ & $<0.001$ \\
\hline \multicolumn{7}{|l|}{ Education } \\
\hline University & 1 & - & - & - & - & - \\
\hline Illiterate & 1.99 & $1.71-2.30$ & $<0.001$ & 1.80 & $1.49-2.17$ & $<0.001$ \\
\hline Primary school & 1.61 & $1.36-1.91$ & $<0.001$ & 1.57 & $1.30-1.88$ & $<0.001$ \\
\hline Middle school & 1.50 & $1.23-1.84$ & $<0.001$ & 1.52 & $1.24-1.87$ & $<0.001$ \\
\hline High school & 1.13 & $0.95-1.35$ & 0.147 & 1.11 & $0.93-1.32$ & 0.231 \\
\hline \multicolumn{7}{|l|}{ Marital status } \\
\hline Married & 1 & - & - & - & - & - \\
\hline Single & 2.59 & $1.53-4.38$ & $<0.001$ & 1.10 & $0.602-2.01$ & 0.753 \\
\hline Widow and divorced & 1.35 & $0.84-2.16$ & 0.211 & 0.705 & $0.41-1.20$ & 0.201 \\
\hline \multicolumn{7}{|l|}{ Locality } \\
\hline Rural & 1 & - & - & - & - & - \\
\hline Urban & 1.70 & $1.47-1.97$ & $<0.001$ & 1.96 & $1.64-2.35$ & $<0.001$ \\
\hline \multicolumn{7}{|l|}{ Smoking status } \\
\hline non-Smoker & 1 & - & - & - & - & - \\
\hline
\end{tabular}




\begin{tabular}{|lllllll|}
\hline Variables & Crude - OR & $\mathrm{Cl} 95 \%$ & P-value & Adjusted OR & Cl 95\% & P-value \\
\hline Smoker & 0.689 & $0.58-0.81$ & $<0.001$ & 1.11 & $0.91-1.36$ & 0.276 \\
\hline Alcohol use & 1 & - & - & - & - & - \\
Non - Alcohol use & & & & & & \\
\hline Alcohol use & 1.26 & $1.09-1.46$ & $<0.001$ & 1.17 & $0.98-1.39$ & 0.074 \\
\hline BMI & & & & & & \\
\hline Normal & 1 & - & - & - & - & - \\
\hline Overweight & 4.37 & $3.64-5.40$ & $<0.001$ & 4.13 & $3.36-5.01$ & $<0.001$ \\
\hline Obese & 13.002 & $10.63-15.89$ & $<0.001$ & 11.17 & $9.02-13.62$ & $<0.001$ \\
\hline * Reference: OR $=1$ & & & & & & \\
\hline
\end{tabular}

